\title{
Use and adoption of Mobile Data Services in Africa: An Empirical Study in Mauritius and South Africa
}

\author{
Hiranjali Ramburn and Jean-Paul Van Belle
}

\begin{abstract}
South Africa and Mauritius both possess among the most advanced mobile telecommunication industries in Africa. However, advanced mobile data services have still not entered the lives of most mobile subscribers. The research objective was to investigate the use and adoption of a number of data services, including content services, web browsing, email, MMS, mobile games, mobile banking and mobile chats in South Africa and Mauritius. We also list the major obstacles and inhibitors mentioned by the respondents as well as what they perceived could be done to promote use and adoption of mobile services. Both quantitative and qualitative research methods have been used. A research instrument was been designed to assess the usage pattern of mobile data services in both countries while a qualitative analysis allowed richer insights to the quantitative findings. The targeted sample included both students and staff from a university and corporate users from various business sectors. The research findings were that, apart from SMS, users were indeed generally slow to adopt the more advanced 3G data services. Interestingly, despite the socio-economic differences in the two countries, many of the barriers identified were similar.
\end{abstract}

Index Terms-Mobile Data Service adoption, barriers to MCommerce, M-Commerce enablers, South Africa, Mauritius.

\section{INTRODUCTION}

There has been a lot of excitement, if not hype, about use of mobile data services and mobile commerce in African countries over the past few years, with predictions that mobile commerce would become the next new trend in the electronic marketplace (Joubert, 2007). Despite huge investments in the sector, the actual adoption and use of mobile data services in most African countries has been particularly slow as compared to countries such as Japan, Taiwan, USA and UK. In Africa, the use of SMS and chat services has been widely accepted, but people are still reluctant to engage in other mobile data services, such as MMS, mobile banking and web browsing amongst others (Brown, Gordon, Janik \& Meyer, 2005).

Although limited research has already been conducted on the adoption of some mobile data services in South Africa, hardly any literature is available in this regard in Mauritius. Therefore, the primary research objective of this investigation is the use of mobile data services in two African countries namely, South Africa and Mauritius. Firstly, the extent to which the various mobile data services have been adopted is investigated. Secondly, the reasons why mobile phone users are reluctant to use different data services and the key inhibitors are explored. Lastly, the factors, which may encourage users to use mobile data services more frequently, are unveiled.

Manuscript received March 11, 2011.

Department of Information Systems, University of Cape Town.
The scope of this research is limited to Business to Consumer (B2C) users of mobile data services in both South Africa and Mauritius. The specific mobile data services which have been investigated in this study are: Cell phone banking, downloading ring tones, games and logos, downloading content such as weather, sport and/or news, web browsing, email, mobile gaming/video, playing online games, short messaging service (SMS), multimedia messaging (MMS), and online chat. These services were selected since they are the most popular and advanced mobile data services available in both South Africa and Mauritius. These two countries were chosen because they already have the required infrastructure for new mobile technologies and services in place, thus the economies of both countries could experience a major boost with the adoption and use of mobile data services (Rouvinen, 2004). This research focuses on the use of mobile phones as opposed to Personal Digital Assistants (PDAs). This is an important distinction to make since PDAs are mostly used by corporate users for business transactions while mobile phones are mainly utilized for individual use (Singh, 2003).

\section{DEFINITIONS AND PRIOR RESEARCH}

Mobile data services are here defined as wireless access to a set of $\mathrm{B} 2 \mathrm{C}$ activities using a mobile phone available through mobile service providers. Examples include transactions, such as SMS, send/receive emails, MMS, mobile games, content services, mobile banking, e-tickets, mobile auctions and stock trading. Some studies have used mobile data services, mobile applications/services or even mobile Internet services interchangeably (Bouwman, Carlsson, Molina-Castillo \& Walden, 2007.

South Africa has one of the most sophisticated telecommunication systems of all emerging markets and ranks 23rd in telecommunications development (Manjoo \& Kankwenda, 2007). The telecommunication sector contributes approximately $6 \%$ to South Africa's GDP. One of the most remarkable occurrences within the South African telecommunication environment has been the rapid adoption rate of mobile phones (Van Wyk \& Van Belle, 2005). The South African mobile industry operates under a unique 3-tier model (Manjoo \& Kankwenda, 2007). The 3 main stakeholders are the Mobile Network Operators (MNOs), Service Providers (SPs) and Wireless Application Service Providers (WASPs). Although South Africa has four MNOs, namely Vodacom, MTN, Cell C and Virgin Mobile, the first two dominate the market and together, hold about 90\% market share. Service Providers (SPs) are in charge of the retailing of mobile products (contracts, handsets, prepaid vouchers and data services) to the general public and corporate users. They are also responsible to manage 
customer relationship on behalf of MNOs. Examples of SPs include Nashua Mobile and AutoPage (Gilham \& Van Belle, 2005). Wireless Application Service Providers (WASPs) are responsible for the creation, promotion and hosting of mobile services. They depend on both SPs and MNOs to provide the infrastructure and customer relationship to offer their services. Examples of WASPs are iTouch, Exact Mobile (Gilham \& Van Belle, 2005).

Similar to South Africa, Mauritius has an advanced telecommunications sector. In fact, Mauritius was the first country to launch cellular operations in the Southern Hemisphere on 29 May 1989 (Minges, Gray \& Tayob, 2004). Unlike other developing nations, Mauritius has a prevalent accessibility of fixed telephonic networks; hence, mobile phones have never been a substitute for fixed telephony. In addition, Mauritius followed the Receiving Party Pays (RPP) system, implying that the person receiving calls was subject to be billed as well. However, as from October 2004, the Island adopted the Calling Party Pays (CPP) regime resulting in a substantial increase in use of mobile phones (Minges et al., 2004). Currently, Mauritius has three Mobile Network Operators namely, Emtel, Cell plus and Mahanagar (MTNL). Cell plus is the current market leader closely followed by EMTEL. MTNL is the latest MNO which entered the market in 2006.

Both Mauritius and South Africa were quick to make significant financial investments for both the purchase of $3 \mathrm{G}$ licenses and rollout of $3 \mathrm{G}$ network infrastructure. Mauritius was the first country in the African continent to launch $3 \mathrm{G}$ services followed by South Africa. The first test call was made on 16 October 2004 by EMTEL in Mauritius and in November 2004, 3G services were available commercially. In South Africa, Vodacom was first to launch $3 \mathrm{G}$ services in December 2004 followed by MTN. In March 2006, MTN launched 3.5G technologies, which make use of High Speed Downlink Packet Access (HSDPA) to provide users with connection speeds of $2 \mathrm{Mbps}$. Vodacom followed in April 2006 (Global UMTS Network Rollout Status, 2006). Mauritius has not yet deployed 3.5G technologies.

Despite the fact that the use of mobile devices is the fastest growing technology ever seen in South Africa, use of advanced mobile data services has still not touched the lives of most cellular phone users in both countries (Goldstuck, 2005). The major portion of the population uses SMS, chat services and some leisure based services such as ring tones and games but they are still reluctant to engage in other more advanced data services (Goldstuck, 2005; Bouwman et al., 2006). Hence, the necessity to investigate the factors which may encourage potential and existing users to adopt and/or continue use of mobile data services.

\section{ENABLERS AND INHIBITORS OF MOBILE DATA SERVICES}

Mobility, convenience and ubiquity are the main benefits of using mobile data services. Internet now travels with the customers; transactions can be conducted from any location and at any time of the day, which makes it well suited for the customers. Information can now be easily accessed at anytime from any location hence ensuring convenience, mobility and ubiquity. However, the actual usability and security of mobile devices have been debated. While some people find using mobile devices to conduct transactions relatively easy, others experience difficulty with the small screen size and small keypad. Data input becomes a problem, and this can lead to wasted time, errors and frustration experienced by users, hence making usability less attractive (Chen \& Frolick, 2004).

Some researchers believe mobile commerce has fewer security flaws as opposed to electronic commerce as the mobile device travels with the user, hence giving the latter a greater sense of security (Brown et al., 2005). However, the mobility of these mobile devices also increases the risk of losing them (Tarasewich, 2003). Mobile users are worried about the safety of their devices as these can easily be lost or stolen. One of the key concerns which emerged during the results analysis of a South African study was: "Although cell phone banking is convenient and more secure in a way, it would be more inconvenient if one loses the phone, because everything will have to be replaced" (Gordon, Janik \& Meyer, 2004).

Cost of mobile data services is another prominent inhibitor. It is one of the major factors to be considered by consumers when deciding whether or not to use a technology or service. Most consumers perceive the cost of mobile data services to be particularly high (Gordon et al., 2004). Mobile phone charges in South Africa can be up to10 times more expensive than that of other comparable European countries and Mauritian charges are comparably high, especially when compared to the relative personal income of Mauritians. Other factors inhibiting use of mobile data services include lack of business requirements, incompatibility of handsets, lack of skills and knowledge concerning the service and poor design interface of the devices (Singh, 2003).

\section{RESEARCH METHODOLOGY.}

The main research objectives relating to the use and adoption of mobile data services were to assess the relative extent to which the various mobile data services have been used and adopted in both South Africa and Mauritius.

'Use' in the context of this research refers to the initial adoption of mobile data services. This is an important distinction to make with other studies as most of them measured the intention to adopt instead of actual use (adoption). Use of mobile data is differentiated by two main phases: an exploration and experimentation phase followed by assessment of experience. Based on their experience, users either choose to adopt mobile data services or to discontinue usage. The research also aimed to determine the main inhibitors and enablers of mobile data services in both countries and to uncover the similarities and differences. A positivist philosophy was adopted. In order to obtain a more accurate picture of the phenomenon under investigation and to enhance the scope and richness of the analysis, a triangulation approach was used by integration of both qualitative and quantitative research approaches (Myers, 1997). A quantitative research approach was initially adopted by sending a questionnaire to a sample of mobile phone users in both countries. Thereafter, a qualitative research approach was undertaken to validate the 
significance of the results obtained through a quantitative lens and to thoroughly understand the different use patterns, inhibitors and enablers of mobile data services in the two countries.

The questionnaire measured the current, previous and future level of use of respondents by focusing on both the variety and frequency of use of the different mobile data services. The respondents were then prompted to state the reason(s) why they are not using any of the mobile data services. A final section asked respondents to rate the three most influential factors which they believe will inhibit or encourage their use.

In order to facilitate comparison between the two countries, we attempted to use a stratified sampling approach with sub-groups based on age, occupation and income. We selected a first select sub-sample in Mauritius and South Africa consisting of university students and staff. Especially students can be seen as an interesting population group because they are young, innovative, sophisticated and well-networked users who are familiar with the mobile technology, accounting for some of the key adoption factors in traditional adoption models. A second sub-sample came from the business environment where people are thought to achieve direct financial and time efficiencies from using the technologies. In Mauritius, owing to the country's small size, the sample is geographically distributed, representing a fair geographical representation of the country's population. In South Africa, the sample is mostly from the Western Cape, an area slightly larger than Mauritius. Even though this may be fairly representative for South Africa in terms of income and age, it is not fully representative of the country's population in terms of other social demographics such as race, language, or culture. This bias, which may or may not affect the findings, is a limitation of this study but was forced on the researchers because of practical feasibility and resource constraints. In Mauritius, 199 usable responses were received whereas in South Africa, 212 usable responses were gathered. These samples are thus almost identical in size and sufficiently large to provide reasonably reliable data.
In the qualitative phase, semi-structured individual interviews were designed to support the quantitative findings. Interviews provide richer insights with regards to respondents' perceptions and experiences of using mobile data services, thus, the differences and similarities unveiled in the quantitative results can be explained qualitatively. Face-to-face interviews were scheduled in both Mauritius and South Africa. Interviewees were given the opportunity to talk freely on their perceptions and experiences of mobile data services but the interviewer occasionally intervened to ensure the interviewees' answers remain pertinent to the area of research. The duration of the interview was 30 minutes. However, 45 minutes sessions were allocated for each interview to allow sufficient time for detailed discussions. At most, two interviews were conducted per day. 13 interviews were carried out in Mauritius while 12 were conducted in South Africa. Interviews in both countries were carried out until a saturation point was reached whereby no richer insights were gained. The same criteria used for the research population of the questionnaires were applied here. Students, academics and working people were targeted. All the interviewees had their own mobile phones and they all had previously either used or experimented with some mobile data services. All the interviews were recorded. Notes were also taken during the interviews. After the initial interviews, the data collected was reviewed and analysed. Although, this process was time consuming and spread over several days, it was still an important phase to uncover whether the data collected was suitable.

\section{DATA ANALYSIS}

\section{A. Demographic Analysis}

The South African ("SA") sample consists of 128 (60\%) males and 84 (40\%) females while the Mauritian ("Mau") sample comprises of 109 (55\%) males and 90 (45\%) females. The gender distribution in both countries is thus fairly comparable. A difference of means ( $\mathrm{t}$-)test between the

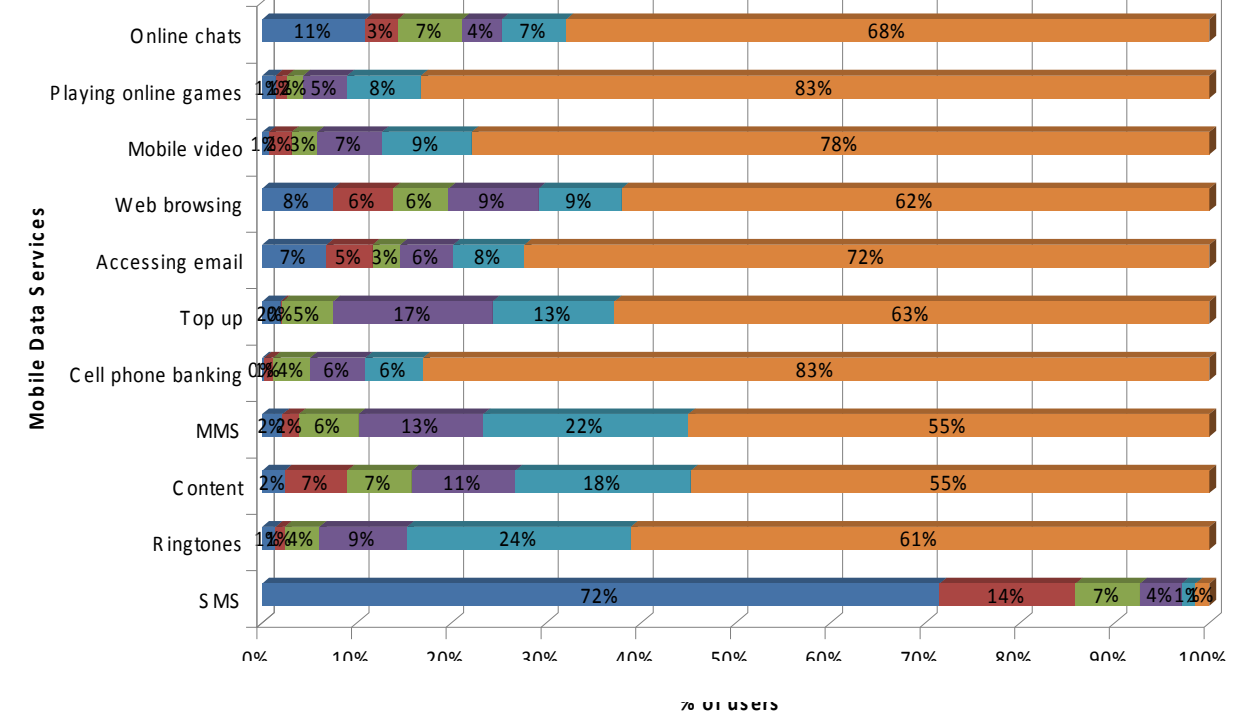

S everal times daily $\square$ Daily $\square$ 2-6 times weekly $\square$ 1-6times montly $\square$ less than once monthly $\square$ Never

Figure 1: Usage Of Mobile Data Services(frequency of use of mobile data services) 
South African and the Mauritian sample yields a p-value of 0.252 , indicating that there is no significant difference in the means of the two countries.

Occupation is another important demographic factor. In both countries, the target sample comprises of both students and working people. The latter consisted of academics, analysts, programmers and software developers, accountants, researchers, administrators, sales people and marketing executives. In South Africa, 53\% of the sample comprises of students and $47 \%$ accounts for working people while the mauritian sample consists $36 \%$ of students and $64 \%$ working people.

With respect to the age distribution, the sample reflects a relatively young user group: more than $40 \%$ of the respondents fall in the 21-25 year age group in both countries. This percentage reflects the stratified sampling approach which targeted students as one of two desired population groups. 15 respondents (8\%) in Mauritius and 39 $(15 \%)$ in South Africa are 20 years old. Only $8-9 \%$ of the sample is older than 40 years. Although people above 40 years old have been targeted, they were either very reluctant to fill in questionnaires or they did not use any of the mobile data services provided.

\section{B. Usage Profile of Mobile Data Services}

This section discusses the usage profile for the various mobile data services, combining both the Mauritian and the South African samples as depicted by Figure 1 below.

Not surprisingly, SMS is the most frequently used service with $72 \%$ of respondents (i.e. 294) using it several times a day. Downloading of content and MMS are each used by $45 \%$ of respondents. $38 \%$ of the sample use web browsing, $32 \%$ use online chat services while $28 \%$ access email from their mobile devices. $22 \%$ of the sample use mobile video. Cell phone banking and playing online games are the least popular services with $83 \%$ of the sample not using these 2 services at all. As for frequency of use, except for SMS, very few respondents use the other services more than once daily. $11 \%$ of the sample (i.e. 45 respondents) use online chats several times daily while $8 \%$ (31) use web browsing and only 7\% (28) use Email more than once daily. Table 1 below provides a more detailed comparison of the individual usage profile of the Mauritian and South African samples.

TABLE I. Mobile Data Services Usage Profile

\begin{tabular}{|c|cc|cc|cc|cc|}
\hline \multirow{2}{*}{ Data Service } & \multicolumn{2}{|c|}{$\mathbf{1 + \text { day }}$} & \multicolumn{2}{|c|}{$\begin{array}{c}\text { 2-6 times } \\
\text { weekly }\end{array}$} & \multicolumn{2}{|c|}{$\begin{array}{c}\text { Less than } \\
\text { monthly } \\
\text { monthly or } \\
\text { Never }\end{array}$} \\
\cline { 2 - 10 } & Mau & SA & Mau & SA & Mau & SA & Mau & $S A$ \\
\hline SMS & $87 \%$ & $84 \%$ & $7 \%$ & $7 \%$ & $4 \%$ & $5 \%$ & $4 \%$ & $2 \%$ \\
\hline Ring tones & $5 \%$ & $0 \%$ & $6 \%$ & $2 \%$ & $11 \%$ & $8 \%$ & $79 \%$ & $90 \%$ \\
\hline Content & $7 \%$ & $11 \%$ & $7 \%$ & $7 \%$ & $13 \%$ & $9 \%$ & $74 \%$ & $72 \%$ \\
\hline MMS & $4 \%$ & $4 \%$ & $4 \%$ & $9 \%$ & $7 \%$ & $19 \%$ & $86 \%$ & $68 \%$ \\
\hline Cell banking & $0 \%$ & $0 \%$ & $4 \%$ & $4 \%$ & $7 \%$ & $5 \%$ & $87 \%$ & $90 \%$ \\
\hline Top Up & $4 \%$ & $1 \%$ & $4 \%$ & $7 \%$ & $20 \%$ & $14 \%$ & $74 \%$ & $77 \%$ \\
\hline EMAIL & $7 \%$ & $17 \%$ & $3 \%$ & $3 \%$ & $4 \%$ & $8 \%$ & $88 \%$ & $72 \%$ \\
\hline Web browsing & $6 \%$ & $22 \%$ & $3 \%$ & $9 \%$ & $3 \%$ & $16 \%$ & $89 \%$ & $53 \%$ \\
\hline Mobile video & $5 \%$ & $2 \%$ & $3 \%$ & $2 \%$ & $7 \%$ & $7 \%$ & $87 \%$ & $89 \%$ \\
\hline Online gaming & $4 \%$ & $1 \%$ & $4 \%$ & $0 \%$ & $6 \%$ & $3 \%$ & $87 \%$ & $95 \%$ \\
\hline Online Chats & $6 \%$ & $22 \%$ & $5 \%$ & $9 \%$ & $2 \%$ & $6 \%$ & $88 \%$ & $63 \%$ \\
\hline
\end{tabular}

The comparison analysis shows that there is a similar usage pattern for services such as SMS, downloading of content and cell phone banking. SMS is the most popular service in both countries. In Mauritius, $76 \%$ of the sample use SMS several times a day and $11 \%$ use it daily while in South Africa, $67 \%$ of the respondents use it more than once daily and $17 \%$ use it daily. Approximately $50 \%$ of the sample use content services in both countries.

The major differences lie in the usage of MMS, web browsing, email, top up and online chats. Whilst MMS, web browsing and email are highly used services in South Africa, very few Mauritians are currently using them. While $61 \%$ of South Africans use MMS, 59\% use web browsing, $45 \%$ use online chats and $37 \%$ use emails, only $28 \%$ of the Mauritians use MMS, 16\% use web browsing and 18\% use online chats and emails. On the other hand, ring tones and top up seem to be more popular in Mauritius with almost $50 \%$ of the Mauritians claiming to download ring tones and $45 \%$ of them using Top Up. Approximately $30 \%$ of the respondents download ring tones and use top up in South Africa.

\section{The Major Reasons Accounting for Non-Use of Mobile Data Services}

In order to identify the barriers to the adoption of mobile data services, respondents were asked to give reasons for not adopting or using data services in an open response field. These were classified by the researchers into categories. Respondents in both countries cite the lack of need for the services as the main reason accounting for non-use of mobile data services. Lack of interest in the services, high cost of transactions and lack of awareness then follow. The major difference lies in the unavailability of the required phone features enabling use of mobile data service. This factor is more prominent among Mauritians.

However, not all of the reasons that are advanced for nonadoption can be seen as inhibitors: lack of need or awareness are not primary inhibitors (though, admittedly, focused marketing can address both by creating a real or perceived need). Key inhibitors to adoption were culled from the literature and users were asked to identify and rank the top three inhibitors. Table 2 lists the major inhibitors of mobile data services in South Africa and Mauritius respectively. Each inhibitor has been grouped in three categories namely; the number of times respondents rated them as the 1st, 2nd or 3rd major inhibitors. A comparison analysis then follows.

TABLE II. BARriers of MobILE DATA SERVICES IN SOUTH AFriCA

\begin{tabular}{|c|c|c|}
\hline $\begin{array}{c}\text { \%o responses rated top 3 barrier } \\
\text { (rank) }\end{array}$ & RSA & Mau \\
\hline Increased cost of services & $59.0 \%(1)$ & $51.8 \%(1)$ \\
\hline Receiving illegal \& harmful content & $36.3 \%(2)$ & $45.2 \%(2)$ \\
\hline Leaking of personal information & $35.4 \%(3)$ & $35.7 \%(3)$ \\
\hline Spamming & $32.1 \%(4)$ & $22.6 \%(7)$ \\
\hline Not knowing what I am paying & $25.5 \%(5)$ & $20.6 \%(8)$ \\
\hline Lack of need & $23.6 \%(6)$ & $26.1 \%(5)$ \\
\hline Billing Errors & $20.3 \%(7)$ & $24.1 \%(6)$ \\
\hline Complexity of handset operation & $15.6 \%(8)$ & $9.5 \%(10)$ \\
\hline Lack of coverage & $14.2 \%(9)$ & $27.1 \%(4)$ \\
\hline Unreliability of technology & $9.9 \%(10)$ & $10.6 \%(9)$ \\
\hline
\end{tabular}

The two countries follow a very similar pattern. In fact, statistically there is no strong indication of difference Spearman's rank correlation coefficient for the top-ranked or combined top-three ranking of the various factors all fail to confirm a null-hypothesis of independence between the 
populations. Increased costs, receiving harmful content and leaking of personal information are the three major inhibitors in both countries. The lack of need for the services, billing errors and lack of knowledge on the cost of services follow closely.

The major difference is seen with regards to lack of network coverage as more Mauritian respondents have rated it as a significant inhibitor as opposed to South African respondents, who rated spamming much higher than the Mauritians. This observation was confirmed in follow-up focus group interviews (for purposes of in-depth qualitative research not reported in this paper) The Mauritian interviewees unanimously expressed their frustration with regards to network coverage while the South African interviewees showed much more satisfaction with their network coverage capability.

\section{The major factors encouraging use of mobile data services}

A similar pattern is exhibited when it comes to the major factors promoting or encouraging the use of mobile data services. Again, the Spearman's rank correlation coefficient (for either the top only or combined top three ranking) does not support the null-hypothesis of a difference in ranking order between the two countries.

The first two major factors influencing use of mobile data services are lower prices of services and a wider range of services in both countries followed by increased awareness of new services and better reliability of services.

TABLE III. THE MAJOR FACTORS ENCOURAGING THE USE OF MOBILE DATA SERVICES

\begin{tabular}{|c|c|c|}
\hline $\begin{array}{c}\text { \% responses rated top 3 } \\
\text { incentive (rank) }\end{array}$ & RSA & Mau \\
\hline Lower prices & $64.6 \%(1)$ & $56.3 \%(1)$ \\
\hline Wider range of services & $32.5 \%(2)$ & $42.7 \%(2)$ \\
\hline Increased awareness & $28.8 \%(3)$ & $28.1 \%(4)$ \\
\hline No PC-based internet & $27.4 \%(4)$ & $17.1 \%(8)$ \\
\hline Reliable services & $25.9 \%(5)$ & $35.2 \%(3)$ \\
\hline Free new handset & $23.6 \%(6)$ & $28.1 \%(4)$ \\
\hline Higher income & $22.2 \%(7)$ & $27.1 \%(6)$ \\
\hline More reliable technology & $21.2 \%(8)$ & $21.1 \%(7)$ \\
\hline Increased security awareness & $10.4 \%(9)$ & $10.6 \%(10)$ \\
\hline Improves image/trendy & $5.2 \%(10)$ & $13.1 \%(9)$ \\
\hline
\end{tabular}

\section{DISCUSSION OF FININGS USING A QUALITATIVE LENS}

The qualitative analysis provided useful insights on the significance of the above listed factors. We discuss the main concerns of mobile data services as perceived by the respondents of the two countries.

$\underline{\text { Cost }}$

The influential impact of cost as both a determinant and inhibitor of mobile data services stand out clearly. This factor is often not given prominence in the research in developed countries. Some of the mobile data services are still relatively expensive, especially when compared to nonAfrican countries. The high costs combined with the relatively lower income - these can be taken together as "affordability" - appear to reduce usage of important services and stop further usage of entertainment-based services. Conversely, lower-priced services are deemed to a major incentive promoting trial ability of new services. In Mauritius, only mobile data services such as SMS and Top Up are priced reasonably while other services are still relatively expensive. Services such as ring tones, content, web browsing, MMS and chats are not popular due to the high cost. Consumers are keen to use services which provide them with 'value for money'. However, at present very few services actually offer them with 'value for money'. On the other hand, in South Africa, services such as downloading of ring tones, MMS and online games, where users have to subscribe to the service provider are still very expensive while services such as chats, cell phone banking and email, where they only pay for the data usage fee are relatively cheaper. Consumers argue that if costs of these services are reduced, people will be encouraged to use them more frequently. Low cost of transactions and promotional costs of services are seen as a major initiative to try new services being introduced

Besides cost of services, cost of mobile handsets is still a major factor inhibiting use of mobile data services. There is currently no contract phones offer in Mauritius, as in other countries, and this is seen as a key inhibitor of use in addition to the relatively high cost of handsets. On the other hand, South Africans using mobile data services extensively have top range handsets and agree that the handset itself is a major factor influencing use of mobile data services. A number of interviewees who are not using mobile data services extensively, state that their current mobile phones do not have the required options for advanced mobile data services and buying a new handset would be too expensive, hence limiting their existing usage.

\section{A. Leaking of personal information and Billing Errors}

Although none of the interviewed sample experienced any type of fraud whereby they have lost confidential information via their mobile phones, they are still apprehensive of the security risks which may arise. They say that if ever they lose confidential information while transacting via their mobile phones, they will be instantly discouraged from using the service again and instantly look for a more secure alternative. Respondents from both countries have voiced their concerns with regards to the monetary risks/issues which may arise while using mobile data services. Respondents say they are unaware of the security measures provided for certain services such as cell phone banking, hence they are apprehensive to transact online with the fear of losing money. South African interviewees mention that they do not think that cell phone banking has been thoroughly tested and totally secure. They are thus very cautious and only use the service on a limited scale to avoid any possible monetary loss. On the other hand, Mauritians perceive mobile data services which are not SMS based to be risky. Mauritian respondents say there is a lack of transparency in the way some services are billed and there is also the fear of the technology not working and still be charged for trying to use the services.

\section{B. Spamming and Invasion of Privacy}

Spamming is seen as a major hindrance leading to invasion of privacy as. Receiving SMS/emails with regards to new mobile data services and mobile technologies is 
acceptable but advertisements that are not focused on mobile products and services are not welcomed. This practice is seen as being distracting and frustrating. Although spamming does not result in instant non-use, it contributes towards decreasing the value derived from using these services thus making the overall use experience less pleasant.

\section{Lack of Need of services/ Functional Efficiency}

A wider range of services, allowing users to be more functionally efficient, would encourage them to engage in more frequent use of mobile data services. Similarly, if users feel that they do not need certain services, they are more likely to stop usage.

Interviewees in both countries cite that they are more likely to use mobile data services only if they need the services and they feel more functionally efficient. They say some mobile data services allow them to be more efficient as things can be done faster and at a low cost. In today's society, use of mobile data services certainly makes one's life easier and more convenient as time is fast becoming a limited resource. People are not willing to waste time while waiting for something/someone or while sitting in traffic, therefore use of certain mobile data services allows them to fill the gap.

\section{Ease of use of services}

Ease of use of mobile data services is associated with the type of handset used. Whilst some phones are quite userfriendly and enhance the overall 'ease of use' experience, others further add to the complexity of use. Ease of use not only refers to whether the use of mobile data services is simple enough for users but also includes the ease of use of the initial set up procedures. The complexity of a technology is more likely to discourage/inhibit use of mobile data services and this is a prominent reason accounting for nonuse of mobile data services, predominantly, by the older generation (mostly people above 40). In both countries, most interviewees say that they are more likely to use mobile data services if they find the mobile data services easy to use and if they can effortlessly operate their handsets.

There is also a distinct relationship between ease of use, computer literacy and occupation. Users who are more technically focused and conversant with computers, struggle less to set up their device and it becomes easy for them to use mobile data services. In contrast, users who are less computer literate and not technically focused rely more on getting help from more technically focused users, call centres and websites to set up and learn how to use mobile data services.

\section{E. Technological Concerns}

Technological concerns refer to network coverage, connectivity and bandwidth issues.

Similar to the quantitative findings, network coverage was not perceived as a major issue in South Africa. Users are mostly satisfied with their network coverage and reliability. On the other hand, in Mauritius users have expressed a general dissatisfaction with the network coverage and reliability. They state that network coverage is so bad that that they have to use all the mobile network operators (MNO) which operate in the country. Whenever they experience network-related problems, they switch over to another MNO.

Unreliability of a service relates to either technology or network failure. A number of respondents found MDS to be unreliable in that aspect. Experiencing minor problems with basic services such as SMS delay is tolerable by most of the users. Minor problems may annoy them for a short while but they would nevertheless continue using the service. However, these experiences make them lose confidence in the service and this may have an adverse effect on experimentation and use of new and more complex services as they expect to experience major problems with more advanced services. Moreover, those who are using advanced services such as MMS, content, mobile video and web browsing are more likely to instantly stop total usage should they find the services to be unreliable.

Poor usability and slow connectivity adversely impact the overall use experience. Interviewees have experienced a lot of connection problems while web browsing and emailing. They find web pages take long to load and sometimes they do not load properly. A number of the Mauritians do not use advanced services like cell phone banking due to the slow connectivity, hence partially accounting for the low usage pattern on cell phone banking in Mauritius as compared to South Africa.

\section{F. Awareness}

Awareness of mobile data services is a distinguished factor that may encourage trial ability and continued use in both countries. Interviewees explicitly state that there is not enough advertising showcasing the different mobile data services currently available on the market. Although there are plenty of advertising concerning services such as ring tones, wallpapers and love poems, there is enough advertising on useful services such as cell phone banking. The current adverts on TV and radio are mainly geared towards making money and are mostly targeted at teenagers. A major reason accounting for non use of services such as msn chats, web browsing and mobile banking is lack of awareness. Although these services exist, they are not being marketed enough, hence the lack of knowledge on behalf of interviewees. In the same way, respondents express their concern with regards to the lack of information on use of useful services. For instance, there is not enough advertising or other means to know which websites are compatible or accessible for use on mobile phones.

Advertising and promotion of new services are strongly associated to trial ability. An increase in advertisements will increase users' awareness and in turn, they will be more interested to try the new services being introduced. However, awareness has different dimensions associated to it whereby the marketing (advertising) of the new services is not enough. The benefits of the new services, the costs of transactions, the security measures provided and the set up procedures are different aspects of marketing which are important to promote visibility.

\section{CONCLUSIONS AND IMPLICATIONS.}

This paper investigated the use and adoption of mobile data services in South Africa and Mauritius. Both countries have advanced mobile telecommunication industries in 
Africa. Amongst the African countries, Mauritius was the first country to launch $3 \mathrm{G}$ technology, followed by South Africa. At present, 3.5G is already available in South Africa. With more than $83 \%$ of the South African population currently using mobile phones, South Africa is the largest cellular market on the African continent, which holds around 78 million cellular users. However, use of advanced mobile data services has still not touched the lives of most mobile subscribers. This research reports on a survey in both countries that looked at the adoption of a number of data services, namely SMS, downloading of ringtones, content services, web browsing, email, MMS, mobile games, mobile banking and mobile chats.

Both quantitative and qualitative research approaches have been used. The questionnaire targeted a sample of more than 400 respondents, divided roughly equally between South Africa and Mauritius was obtained. The samples were comparable with regards to gender and age. On the other hand, a total number of 25 interviews were conducted in both countries. Use of both research approaches has ensured better quality and validity of the results. The results from each country were also compared to one another to assess any similarities and differences.

The usage profile shows that SMS is the most widely used service in both countries. MMS, web browsing, emails and chats are relatively popular in South Africa while the use of ring tones and top ups are more prominent in Mauritius. MMS, emails, web browsing and chats are not widely used in Mauritius. The main inhibitors of mobile data services are mostly cost-related and include the high cost of transactions, billing errors and lack of visibility of transaction costs. Other prominent inhibitors include reception of harmful content, leakage of personal information, spamming and lack of (perceived) need of the services. Lower prices of transactions, a wider range of services and increased awareness were cited as the major factors influencing use of mobile data services.

This research leads to a number of practical recommendations. Lack of awareness is a major problem in both countries, therefore more adverts and promotional campaigns could increase consumer knowledge about the new services being introduced and their possible benefits. However, the adverts should focus on educating the consumers with regards to the specific benefits of the services in terms of efficiency and effectiveness and the advantages of using them as opposed to other alternatives.

Cost was found to have a strong inhibiting impact on use. Therefore, the cost of a number of services should be lowered to boost up use of mobile data services. New services should be introduced at a relatively low price for a specific time period to promote trial ability. There needs to be increased transparency with regards to the billing and cost of some transactions. Furthermore, the stakeholders in
Mauritius may consider the option of providing contract phones to their consumers as the cost of capable handsets is currently seen as a major inhibitor of use.

\section{REFERENCES}

[1] Bouwman, H., Carlsson, C., Molina-Castillo, F. \& Walden, P. (2007). Barriers and drivers in the adoption of current and future mobile services in Finland. Telematics and Informatics, vol.24, no.2, pp.145160 .

[2] Brown, I., Cajee, Z., Davies, D. \& Stroebel, S. (2003). Cell phone banking predictors of adoption in South Africa - an exploratory study. International Journal of Information Management, vol.23, no.3, pp.381-393.

[3] Brown, I., Gordon, C., Janik, N. \& Meyer, M. (2005). Investigating adoption/non-adoption of cell Phones for financial transactions in South Africa. Proceedings of the 16th Australasian Conference on Information Systems, 20th November-2nd December 2005, Sydney; Australia.

[4] Chen, L. \& Frolick, M. (2004). Assessing M-commerce opportunities. Information Systems Management, vol. 21 no.2, pp.53-61.

[5] Gilham, C. Van Belle, J.P. Factors Affecting the Adoption of Mobile Content Services amongst Youth in the Western Cape, South Africa Proceedings of the 4th International Business Information Management Conference (IBIMA), Lisbon (Portugal), 5-7 July 2005.

[6] Global Network Rollout Status. (2005). 3G South Africa 3G/UMTS/HSDPA Network Rollout Status: Statistics and network Information. [Online] Available at: www.3g.co.za/content/view/23/33 [Accessed June 2008]

[7] Goldstuck, A. (2005). The Goldstuck Report: Mobile banking in South Africa. [Online] Available at: http://www.theworx.biz/MOBILE05.htm [Accessed April 2008]

[8] Gordon, C., Janik, N. \& Meyer, M. (2004). The non-adoption of cell phones for financial transactions - a qualitative study. Empirical Report, Cape Town; Department of Information Systems, Faculty of Commerce, UCT.

[9] Joubert, J. (2006). The importance of Trust in M-commerce. Masters Report, Cape Town; Department of Information Systems, Faculty of Commerce, UCT.

[10] Kaasinen, E. (2005). User acceptance of mobile services- value, ease of use, trust and ease of adoption. Finland: VTT publications. [Online] Available at: http://www.vtt.fi/inf/pdf/publications/2005/P566.pdf [Accessed June 2008]

[11] Manjoo, S. \& Kankwenda, G. (2007). The uses and gratifications of mobile internet in South Africa. Empirical Research, Cape Town; Department of Information Systems, Faculty of Commerce, University of Cape Town.

[12] Minges, M., Gray, V. \& Tayob, M. (2004). The Fifth Pillar: Republic of Mauritius ICT Case Study. International Telecommunication Union. [Online] Available at: www.itu.int/itudoc/gs/promo/bdt/cast_int/86187.html [Accessed June 2008]

[13] Rouvinen, P. (2004). Diffusion of mobile telephony: Are developing countries different? Proceedings of UNU- WIDRER conference, 2004; Finland.

[14] Singh, I.K. (2003). Mobile commerce: Usage and usability. Proceedings of the 4th Word Wide Web Applications Conference, 46th September, University of Stellenbosch, Cape Town; South Africa.

[15] Tarasewich, P. (2003). Designing Mobile commerce applications. Communications of the ACM, vol.46, no.12, pp.57-60.

[16] Van Wyk, S. \& Van Belle, J.P. (2005). Adoption Factors for Mobile Gaming in South Africa. Proceedings of the 5th International Business Information Management Conference (IBIMA), 13-15th December 2005, Cairo; Egypt. 